\title{
Postoperative Complications and Associated Factors Among Surgical Patients Treated at a Tertiary Hospital, Eastern Ethiopia: A Prospective Cohort Study
}

\author{
Badhaasaa Beyene Bayissa (iD) \\ Mohammad Mummud' \\ Fufa Miressal \\ Gelana Fekadu iD ${ }^{2}$ \\ 'Department of Surgery, School of \\ Medicine, College of Health and Medical \\ Science, Haramaya University, Harar, \\ Ethiopia; ${ }^{2}$ Department of Nursing, School \\ of Nursing and Midwifery, College of \\ Health and Medical Science, Haramaya \\ University, Harar, Ethiopia
}

Background: Surgical intervention is one of the core components of the health care system, yet not free of risks. Once postoperative complications occur, patients are subjected to extra costs for treatment, longer hospital stay, and associated disabilities. The chance of death also increases once patients develop postoperative complications. However, the extent of in-hospital postoperative complications was not well studied in Ethiopia, particularly in the Eastern part of the country. As a result, this study was aimed to determine the magnitude of postoperative complications and to identify associated factors among surgical patients treated at a tertiary hospital, eastern Ethiopia. Methods: A prospective cohort study was conducted from July 1, 2019 to January 30, 2020. Patients from general surgery, neurosurgery, orthopedic, and pediatric surgery were incorporated into the study. The calculated sample size was 384 using single population formulas. Data were analyzed using SPSS version 23. Bivariable and multivariable logistic regression analyses were conducted to identify factors associated with postoperative complications. The significance level of associations was considered with a $P$-value $<0.05$ and an adjusted odds ratio (AOR) at a $95 \%$ confidence interval(CI).

Results: 8The magnitude of postoperative complications was $12.5 \%$ (95\% CI=9.4-16.2\%). From those who had developed postoperative complications, 20.5\% were deceased. Factors associated with postoperative complications were cigarette smoking ( $\mathrm{AOR}=4.02,95 \% \mathrm{CI}=1.86$ 8.66), patients with a morbidity status according to the American Society of Anesthesiologists (ASA) category $2(\mathrm{AOR}=7.83 ; 95 \% \mathrm{CI}=2.95-20.75)$, ASA 3 (AOR=9.62; 95\% $\mathrm{CI}=1.70-54.46)$, and ASA $4(\mathrm{AOR}=3.25 ; 95 \% \mathrm{CI}=1.22-8.60)$, operative hours of $1-2$ hours duration $(\mathrm{AOR}=3.38$; $95 \% \mathrm{CI}=1.45-7.94)$, operative hours of more than 2 hours ( $\mathrm{AOR}=4.36 ; 95 \% \mathrm{CI}=1.91-9.95)$, and intraoperative complications ( $\mathrm{AOR}=5.96 ; 95 \% \mathrm{CI}=1.707-20.87$ ).

Conclusion: This study showed a higher proportion of postoperative complications associated mortality rates compared to similar studies across the world. The majority of patients who developed complications and died were those who were operated on on an emergency basis. This mandates to follow the damage control surgery protocol, though further study might be needed to sort out the likely causes for this increased risk.

Keywords: surgical outcome, postoperative complications, Haramaya University

\section{Introduction}

Surgery is an essential component of the health care system. ${ }^{1}$ More than 230 million major surgical procedures are undertaken worldwide each year. Even though the overall risk of complication is low; there are high risk groups who tend
Correspondence: Badhaasaa Beyene Bayissa

Email badhok@gmail.com 
to develop postoperative complications. ${ }^{2}$ For instance, about $10 \%$ of patients undergoing surgery in the UK are at high risk of complications. Applying this to the global rate, every year up to 25 million patients undergo high-risk surgical procedures; of which three million do not survive until hospital discharge. ${ }^{2,3}$

Postoperative complications are an important cause of death $^{3,4}$ among patients who underwent surgeries. It culminates in increased treatment costs, reduces life expectancy, and reduces quality-of-life among patients who survived to leave the hospital. ${ }^{5}$ Moreover, effective perioperative and intraoperative care is considered essential for the safe provision of surgical treatments, the optimal level of such care has not been defined and the understanding of outcomes after surgery remains scarce. ${ }^{6}$

The magnitude of postoperative complications varies depending on the quality of service, availability of human resources and materials in health care facilities. ${ }^{7}$ According to the study conducted in one tertiary hospital in Ethiopia, the prevalence of postoperative complications were $39.2 \%$ among patients who underwent emergency laparotomies $^{8}$ and $17 \%$ among patients who were surgically treated for an acute abdomen. ${ }^{9}$

Moreover, studies established factors linked with postoperative complications include; smoking, ${ }^{10}$ higher body mass index, combined organ resection, ${ }^{11}$ older age, comorbidities, ${ }^{8,12}$ longer duration of surgery, anesthesia, ${ }^{13,14}$ intraoperative adverse events, ${ }^{15,16}$ and higher ASA class. ${ }^{17,18}$

In Ethiopia, the lack of adequate skilled human resources, inadequate surgical equipment, and supplies has endangered the limited surgical procedure's safety and success. ${ }^{19}$

In 2016, the Ethiopian Federal Ministry of Health (FMOH) has launched the initiative "saving lives through safe surgery" (SaLTS), and strategic plans for improving infrastructure development which entail necessary health facility buildings that are critical for the smooth functioning of the OR, recovery, and central sterilization services and other adjoining structures. The initiative was developed to ensure the delivery of quality, safe, essential, and emergency surgery throughout the country to alleviate the national burden of diseases, disability, and death that are preventable throughout safe surgery. ${ }^{20}$

However, there is a dearth of epidemiologically reliable and methodologically sound studies on postoperative complications among surgical patients, particularly in the eastern part of the country. Therefore, the aim of this study was to assess the magnitude and factors associated with postoperative complications among surgical patients operated on in Hiwot Fana Specialized University Hospital, which can greatly contribute to the uncharted surgical outcome information in the country in general and our setup in particular.

\section{Methods and Materials Study Period and Setting}

The study was conducted from July 1, 2019 to January 30, 2020 at Hiwot Fana specialized university hospital, which is located in Harar town, eastern Ethiopia, $526 \mathrm{~km}$ from the capital city, Addis Ababa. The hospital provides basic and advanced health care for over 5 million people living in the Harari region, the two zones of Hararge from Oromia regional state and the Somali region.

\section{Study Design and Populations}

A prospective observational cohort study design was used. All patients who were admitted to a surgical ward, which includes general surgery, orthopedics, pediatrics, and neurosurgical patients were used as the source population and all patients who underwent surgical intervention (emergency and elective) during the study period were considered as the study population. The case mixes were available for all the above surgical units as an elective as well as emergency but emergency cases outnumber elective case for different reasons. Patients readmitted within 30 days of surgery, patients from the gynecology and obstetrics department, patients in day care surgeries; those who were operated at other health facilities, and referred to a study setting were excluded.

\section{Sample Size and Sampling Procedure}

The single population proportion formula was employed to calculate the sample size by considering the assumptions: standard normal distribution $(Z=1.96)$, with a onfidence interval of $95 \%$ and $\alpha=0.05$; prevalence of postoperative complication $(P=39.2 \%),{ }^{8}$ margin of error $(d=5 \%)$. The sample final size was calculated to be 384 after adding a $5 \%$ non-response rate.

\section{Data Collection Tools and Procedure}

Data were collected using a semi-structured questionnaire adapted from the international surgical outcome study and by reviewing other relevant literature with modifications to the local setup. , $6,8,16$ The tool was divided into different parts, including: socio-demographic characteristics, patient 
underlying medical or surgical conditions, intraoperative factors (length of surgical procedure, length of anesthesia time, type of anesthesia used, and occurrences of intraoperative adverse events), and a postoperative course was followed for development of complications (infectious and noninfectious), types of complications, intensive care unit admission, reoperation, and patient outcome at discharge. The data were collected through interviewer-administered technique from the patient him/herself/patient's attendant and the patient's medical record chart review while the patient was under care. The minimum follow-up was conducted until discharge with the maximum extension of 30 days for patients with delayed discharge. The questionnaire was first prepared in the English language and translated to the local languages (Afaan Oromo and Amharic) for the actual data collection. It was translated back to the English language during the data entry by a person who was proficient in both English and the local languages. The patient's medical record review was conducted in English. Six surgery residents (general practitioners who were specializing in general surgery) participated in the data collection.

\section{Data Processing and Analysis}

The data were checked for completeness, cleared, and entered into Epidata version 7. Analysis was made using statistical package for social science (SPSS) version 23 (SPSS, Chicago, IL). Characteristics of patients were presented with descriptive statistics such as frequency, percentage, and mean. Bivariable and multivariable logistic regression analysis was conducted to test the association between the independent and outcome variables. Those variables with a $P$-value less than 0.25 at a $95 \%$ confidence interval during bivariable logistic regression analysis were further analyzed with multivariable logistic regression. Adjusted Odds ratio was calculated and variables with a $P$-value $<0.05$ were considered as statistically significant. Model fitness was checked with HosmerLemeshow goodness of fit.

\section{Data Quality Control}

We provided training for data collectors on the tool components, method of data collection, and ethical approach prior to the actual data collection. Additionally, we conducted a pretest among 20 patients ( $5 \%$ of the sample size) at Haramaya general hospital, which is $20 \mathrm{~km}$ away from Harar town to the west. Based on the pre-test result we modified the tool and followed the whole data collection procedures strictly.

\section{Operational Definitions}

Postoperative complication/surgical outcome - Definitions were included for 22 individual complications. Most adverse events occur as a consequence of tissue injury due to surgery or anesthesia, in combination with patient age, frailty, and comorbid disease, rather than as a result of technical failure or medical error. ${ }^{21}$

Pneumonia - CDC (center for disease control) definition is used. ${ }^{22}$

Surgical site infections - again, the CDC definition of different SSIs are used. ${ }^{22}$

\section{Results}

\section{Socio-Demographic Characteristics}

A total of 352 patients were included in the study, with a response rate of $91.6 \%$. Two hundred and seventy-four $(77.8 \%)$ of them were male, making the male-to-female ratio $3.5: 1$. The overall mean age of the patients was 30.3 \pm 18.2 (SD) years (Table 1 ).

\section{Clinical and Perioperative Characteristics} Concerning the preoperative diagnosis of patients, 137 $(38.9 \%)$ were operated on as a result of an acute surgical abdomen, followed by all types of trauma (116, 33.0\%). Fifteen (4.2\%) study participants had underlying chronic medical comorbidities. The patient's morbidity status was categorized according to the American Society of Anesthesiologists (ASA). Accordingly, 199 (56.5\%) of them were ASA1. General anesthesia was used for more than three quarters (280, $79.5 \%$ ) of patients. In 137 (38.9\%) patients, the operation time took 1-2 hours and an intraoperative adverse event occured in seven $(2 \%)$ patients (Table 2$)$.

Table I Socio-Demographic Characteristics of Patients Operated on at Hiwot Fana Specialized University Hospital, Harar, 2020/2I

\begin{tabular}{|l|l|l|l|}
\hline \multicolumn{2}{|l|}{ Variables } & Frequency & Percent \\
\hline Sex & Male & 274 & 77.8 \\
& Female & 78 & 22.2 \\
\hline Age & $\leq 14$ & 64 & 17.9 \\
& $15-24$ & 82 & 23.6 \\
& $25-34$ & 77 & 21.9 \\
& $35-44$ & 50 & 14.2 \\
& $45-55$ & 35 & 9.9 \\
& $>55$ & 44 & 12.5 \\
\hline Residence & Urban & 142 & 40 \\
& Rural & 210 & 60 \\
\hline
\end{tabular}


Table 2 Clinical and Perioperative Characteristics of Patients Operated on at Hiwot Fana Specialized University Hospital, Harar, 2020/ 21

\begin{tabular}{|c|c|c|c|}
\hline Variables & & Frequency $(\mathbf{N})$ & Percent (\%) \\
\hline Preoperative diagnosis & $\begin{array}{l}\text { Trauma } \\
\text { Acute abdomen } \\
\text { Urologic disorders } \\
\text { Endocrine disorders } \\
\text { Orthopedic cases } \\
\text { Elective neurosurgery } \\
\text { Hernia } \\
\text { Others }\end{array}$ & $\begin{array}{l}116 \\
137 \\
20 \\
11 \\
9 \\
2 \\
12 \\
45\end{array}$ & $\begin{array}{l}33 \\
38.9 \\
5.7 \\
3.1 \\
2.6 \\
0.6 \\
3.4 \\
12.8\end{array}$ \\
\hline Comorbidity & $\begin{array}{l}\text { No } \\
\text { Yes }\end{array}$ & $\begin{array}{l}337 \\
15\end{array}$ & $\begin{array}{l}95.8 \\
4.2\end{array}$ \\
\hline Morbidity status & $\begin{array}{l}\text { ASA I } \\
\text { ASA II } \\
\text { ASA III } \\
\text { ASA IV }\end{array}$ & $\begin{array}{l}199 \\
23 \\
102 \\
28\end{array}$ & $\begin{array}{l}56.5 \\
6.5 \\
29.0 \\
8.0\end{array}$ \\
\hline Types of anesthesia & $\begin{array}{l}\text { General anesthesia } \\
\text { Spinal anesthesia } \\
\text { Local anesthesia }\end{array}$ & $\begin{array}{l}280 \\
51 \\
21\end{array}$ & $\begin{array}{l}79.5 \\
14.5 \\
6.0\end{array}$ \\
\hline Duration of anesthesia & $\begin{array}{l}<60 \text { minutes } \\
60-120 \text { minutes } \\
>120 \text { minutes }\end{array}$ & $\begin{array}{l}104 \\
137 \\
111\end{array}$ & $\begin{array}{l}29.5 \\
38.9 \\
31.5\end{array}$ \\
\hline Duration of surgery & $\begin{array}{l}<60 \text { minutes } \\
60-120 \text { minutes } \\
>120 \text { minutes }\end{array}$ & $\begin{array}{l}119 \\
137 \\
96\end{array}$ & $\begin{array}{l}33.8 \\
38.9 \\
27.3\end{array}$ \\
\hline Types of procedure & $\begin{array}{l}\text { Orthopedic } \\
\text { Upper gastrointestinal } \\
\text { Lower gastrointestinal } \\
\text { Urologic } \\
\text { Endocrine } \\
\text { Thoracic } \\
\text { Neurosurgery } \\
\text { Hernia repair } \\
\text { Others* }\end{array}$ & $\begin{array}{l}82 \\
39 \\
128 \\
20 \\
11 \\
7 \\
31 \\
12 \\
22\end{array}$ & $\begin{array}{l}23.3 \\
11.1 \\
36.4 \\
5.7 \\
3.1 \\
2.0 \\
8.8 \\
3.4 \\
6.3\end{array}$ \\
\hline Intraoperative adverse events & $\begin{array}{l}\text { No } \\
\text { Yes }\end{array}$ & $\begin{array}{l}345 \\
7\end{array}$ & $\begin{array}{l}98.0 \\
2.0\end{array}$ \\
\hline Types of intraoperative adverse events & $\begin{array}{l}\text { latrogenic injury } \\
\text { Cardiac arrest }\end{array}$ & $\begin{array}{l}6 \\
1\end{array}$ & $\begin{array}{l}85.7 \\
14.3\end{array}$ \\
\hline Urgency of the operation & $\begin{array}{l}\text { Emergency } \\
\text { Elective }\end{array}$ & $\begin{array}{l}268 \\
84\end{array}$ & $\begin{array}{l}76.1 \\
23.9\end{array}$ \\
\hline Postoperative complication & $\begin{array}{l}\text { No } \\
\text { Yes }\end{array}$ & $\begin{array}{l}308 \\
44\end{array}$ & $\begin{array}{l}87.5 \\
12.5\end{array}$ \\
\hline In-hospital death & $\begin{array}{l}\text { Yes } \\
\text { No }\end{array}$ & $\begin{array}{l}9 \\
343\end{array}$ & $\begin{array}{l}2.5 \\
97.5\end{array}$ \\
\hline
\end{tabular}

Note: *Others: lumpectomy, oral and maxillofacial.

Abbreviation: ASA; American Society of Anesthesiologists. 


\section{Postoperative Complications and Patient Outcomes}

Postoperatively, forty-four $(12.5 \% ; 95 \% \mathrm{CI}=9.4-16.2 \%)$ patients developed different types of complications while they were under inpatient care and follow-up (Figure 1). Among patients with postoperative complications, 33 (75\%) developed hospital acquired infection; from which surgical site infection accounted for $31(94 \%)$ and two (6\%) had pneumonia. Concerning the types of surgical site infection, $21(63.6 \%)$, nine (27\%), and three (9.4\%) were superficial, deep, and organ/ space infection, respectively. Five (11.4\%) developed both surgical site infection and hospital acquired pneumonia, out of which four $(80 \%)$ died. Fourteen $(4 \%)$ patients were reoperated on in the hospital. Nine patients died in the facility, making the in-hospital mortality rate of $2.5 \%$ after surgery. The mean length of postoperative hospital stay was 5.4 days ( \pm 4.8 $\mathrm{SD})$ and those who developed postoperative complication

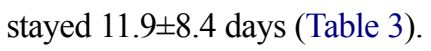

Among patients with postoperative complications, 14 $(31.8 \%)$ and $11(25 \%)$ had a morbidity status of ASA3 and ASA4, respectively (Figure 2).

\section{Factors Associated with Postoperative Complications}

Upon crude analysis; sex, age, cigarette smoking status, patient morbidity status, intraoperative adverse events
(IAE), length of anesthesia time, and length of operation time were found to be significantly associated with postoperative complications. After controlling for confounding factors; cigarette smoking, patients morbidity status ASA more than category II, duration of surgery, and intraoperative adverse events were significantly associated with postoperative complications at a $P$-value $<0.05$ and $95 \%$ CI.

Smokers were $4(\mathrm{AOR}=4.02,95 \% \mathrm{CI}=1.86-8.66)$ times more likely to develop postoperative complications compared to nonsmokers. Whereas, patients with a morbidity status (ASA) category of ASA2, ASA3, and ASA4 were 7.8 $(\mathrm{AOR}=7.83 ; 95 \% \mathrm{CI}=2.95-20.75), 9.6(\mathrm{AOR}=9.62 ; 95 \%$ $\mathrm{CI}=1.70-54.46)$ and $3.2(\mathrm{AOR}=3.25 ; 95 \% \mathrm{CI}=1.22-8.60)$ times more likely to develop postoperative complications, respectively, than patients with a category ASA 1.

Patients who have stayed under surgery for 1-2 hours were $3.4(\mathrm{AOR}=3.38 ; 95 \% \mathrm{CI}=1.45-7.94)$ times more likely to develop complications than those who stayed for less than 1 hour under surgery. In the same way, patients who stayed more than 2 hours under anesthesia were $4.36(\mathrm{AOR}=4.36 ; 95 \% \mathrm{CI}=1.91-9.95)$ times more likely to develop postoperative complications than those who remained under anesthesia for less hours.

Patients who had intraoperative adverse events; like iatrogenic injury and cardiac arrest; were $6(\mathrm{AOR}=5.96 ; 95 \%$

\section{key}

Wurgical site infection $\approx$ Pneumonia II Both Surgical site inection and Pneumonia $\approx$ cardiac arrest $=$ Others

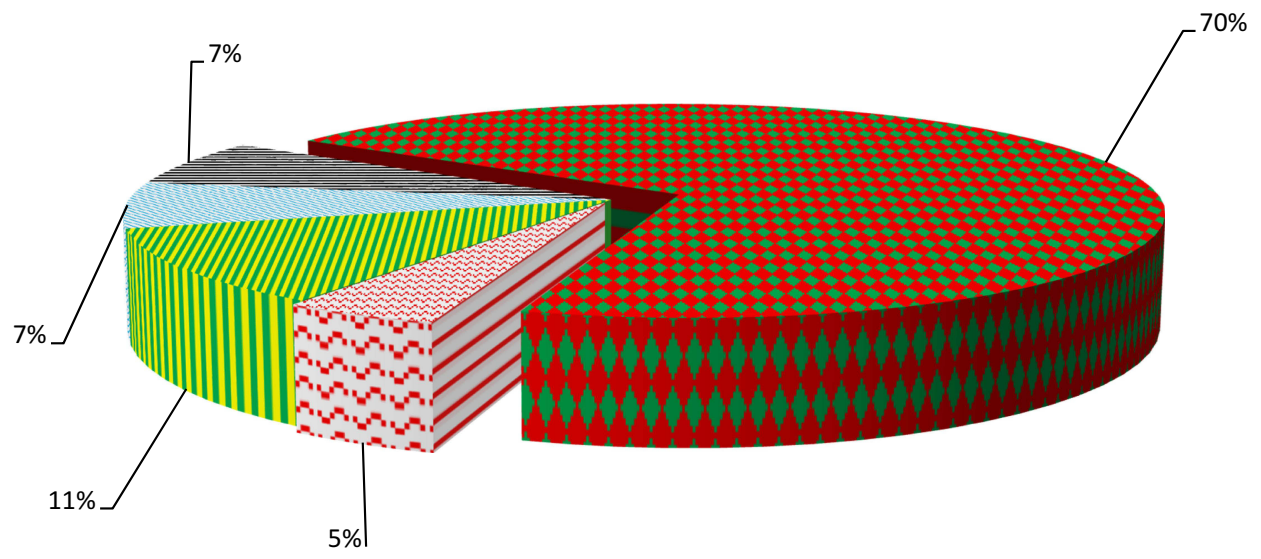

Figure I Types of perioperative complications developed in patients operated on in HFSUH, Harar, 2020/2I. 
Table 3 Cross-Tabulation for Postoperative Complications and Patients Outcome at Discharge Among Patients Operated on at Hiwot Fana Specialized University Hospital, Harar, 2020/21

\begin{tabular}{|c|c|c|c|c|}
\hline \multicolumn{2}{|l|}{ Variables } & \multicolumn{3}{|c|}{ Patient's Outcome at Discharge } \\
\hline & & \multirow{3}{*}{$\begin{array}{l}\text { Alive } \\
308(100 \%) \\
35(79.5 \%)\end{array}$} & \multirow{3}{*}{$\begin{array}{l}\text { Died } \\
0 \\
9(20.5 \%)\end{array}$} & \multirow{3}{*}{$\begin{array}{l}\text { Total } \\
308(100 \%) \\
44(100 \%)\end{array}$} \\
\hline Postoperative complications & No & & & \\
\hline & Yes & & & \\
\hline \multirow[t]{4}{*}{ Types of complication } & Hospital acquired infection & 32 (94\%) & $2(6 \%)$ & $33(100 \%)$ \\
\hline & Cardiac arrest & 0 & $3(100 \%)$ & $3(100 \%)$ \\
\hline & Both SSI and pneumonia & I (20\%) & $4(80 \%)$ & $5(100 \%)$ \\
\hline & $*$ Others & $3(100 \%)$ & 0 & $3(100 \%)$ \\
\hline \multirow[t]{2}{*}{ Types of hospital acquired infection } & SSI & $30(79 \%)$ & I (3\%) & $31(100 \%)$ \\
\hline & Pneumonia & I (50\%) & I (50\%) & $2(100 \%)$ \\
\hline \multirow[t]{2}{*}{ Intensive care unit admission } & No & $343(99 \%)$ & $3(1 \%)$ & $346(100 \%)$ \\
\hline & Yes & $3(50 \%)$ & $3(50 \%)$ & $6(100 \%)$ \\
\hline \multirow[t]{2}{*}{ Reoperation } & No & $330(97.6 \%)$ & $8(2.4 \%)$ & $338(100 \%)$ \\
\hline & Yes & $13(92.8 \%)$ & I (7.2\%) & $14(100 \%)$ \\
\hline \multicolumn{2}{|l|}{ Overall LOHS in days, mean (SD) } & \multicolumn{3}{|l|}{$5.4 \pm 4.8$} \\
\hline \multicolumn{2}{|c|}{ LOHS for complicated patients (days \pm SD) } & \multicolumn{3}{|l|}{$11.9 \pm 8.4$} \\
\hline
\end{tabular}

Note: *Others: hemorrhage, respiratory and urinary complications.

Abbreviations: SD, Standard deviation; LOHS, length of hospital stay; SSI, surgical site infection.

$\mathrm{CI}=1.71-20.87$ ) times more likely to develop Discussion

complications as compared to those without incident The magnitude of postoperative complications according to (Table 4). our study was $12.5 \%$, which is similar to the global outcome

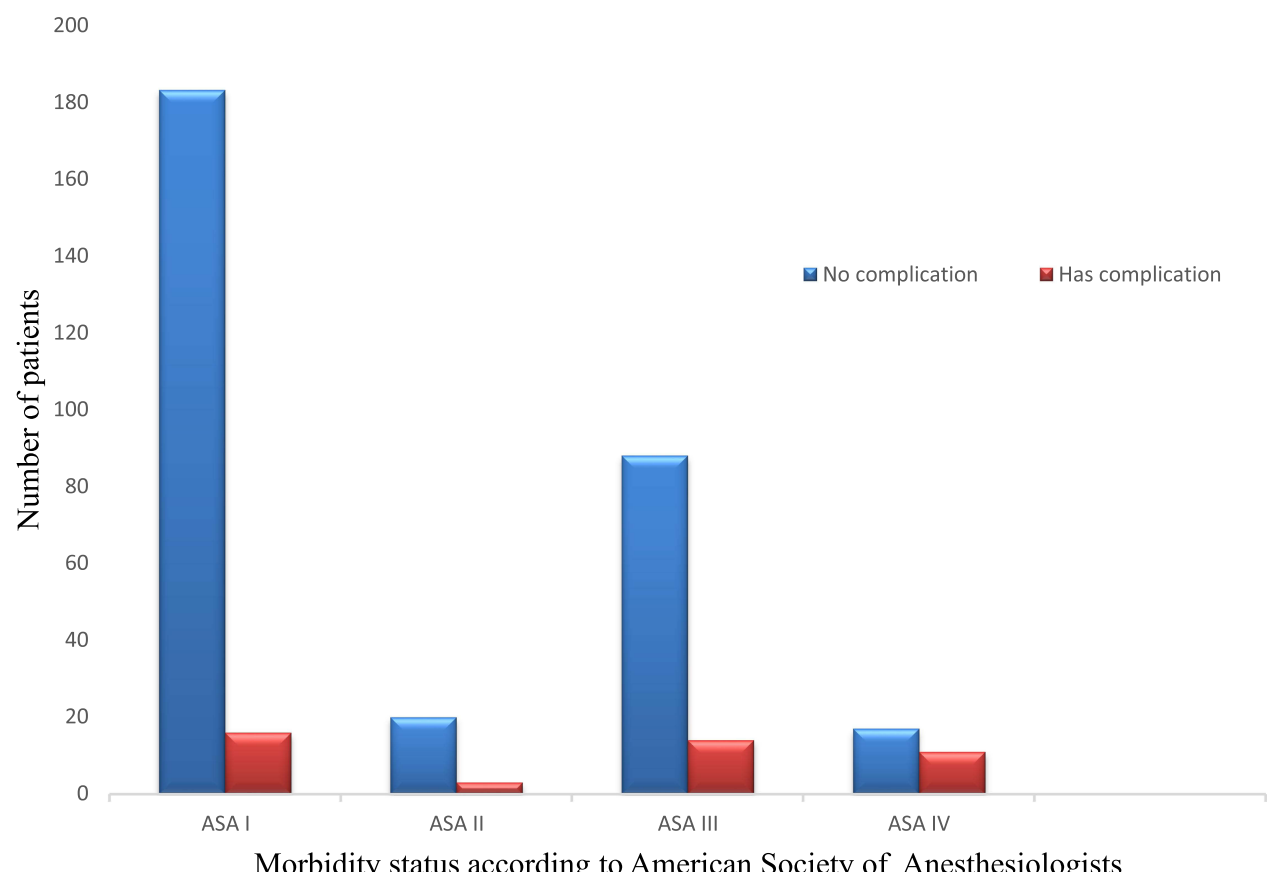

Figure 2 The proportion of postoperative complication for different categories of the American Society of Anesthesiologists (ASA) among patients operated on at Hiwot Fana Specialized University Hospital, Harar, 2020/2I. 
Table 4 Factors Associated with Postoperative Complications Among Patients Operated on at Hiwot Fana Specialized University Hospital, Harar, 2020/2I

\begin{tabular}{|c|c|c|c|c|c|}
\hline \multirow[t]{2}{*}{ Characteristics } & \multirow[t]{2}{*}{ Category } & \multicolumn{2}{|c|}{ Postoperative Complication } & \multirow[t]{2}{*}{ COR $(95 \% \mathrm{CI})$} & \multirow[t]{2}{*}{ AOR $(95 \% \mathrm{Cl})$} \\
\hline & & No $(n=308)$ & Yes $(n=44)$ & & \\
\hline Sex & $\begin{array}{l}\text { Male } \\
\text { Female }\end{array}$ & $\begin{array}{l}234 \\
73\end{array}$ & $\begin{array}{l}40 \\
5\end{array}$ & $\begin{array}{l}\text { I } \\
0.39(0.13-1.22)\end{array}$ & $\begin{array}{l}\text { I } \\
0.490(0.15-1.53)\end{array}$ \\
\hline Smoking status & $\begin{array}{l}\text { No } \\
\text { Yes }\end{array}$ & $\begin{array}{l}266 \\
42\end{array}$ & $\begin{array}{l}32 \\
12\end{array}$ & $3.19(1.63-6.21)$ & $\begin{array}{l}\text { I } \\
4.02(1.86-8.66)^{* *}\end{array}$ \\
\hline Set of operation & $\begin{array}{l}\text { Emergency } \\
\text { Elective }\end{array}$ & $\begin{array}{l}233 \\
75\end{array}$ & $\begin{array}{l}35 \\
9\end{array}$ & $1.30(0.53-3.18)$ & I. \\
\hline Patient morbidity status & $\begin{array}{l}\text { ASA } 1 \\
\text { ASA } 2 \\
\text { ASA } 3 \\
\text { ASA } 4\end{array}$ & $\begin{array}{l}183 \\
21 \\
86 \\
17\end{array}$ & $\begin{array}{l}16 \\
2 \\
16 \\
11\end{array}$ & $\begin{array}{l}\text { I } \\
8.96(2.96-25.48) \\
13.23(1.92-91.18) \\
3.21(1.17-8.80)\end{array}$ & $\begin{array}{l}\text { I } \\
7.83(2.95-20.75)^{* *} \\
9.62(1.70-54.46)^{*} \\
3.25(1.22-8.60)^{*}\end{array}$ \\
\hline Type of anesthesia & $\begin{array}{l}\text { GA } \\
\text { SA } \\
\text { LA }\end{array}$ & $\begin{array}{l}242 \\
45 \\
20\end{array}$ & $\begin{array}{l}38 \\
6 \\
1\end{array}$ & $\begin{array}{l}\text { I } \\
0.333(0.02-4.79) \\
0.580(0.05-7.02)\end{array}$ & $\begin{array}{l}\text { I } \\
0.62(0.05-7.19) \\
0.42(0.037-4.87)\end{array}$ \\
\hline Duration of anesthesia (minutes) & $\begin{array}{l}\leq 60 \\
60-120 \\
>120\end{array}$ & $\begin{array}{l}97 \\
125 \\
86\end{array}$ & $\begin{array}{l}7 \\
12 \\
25\end{array}$ & $\begin{array}{l}\text { I } \\
0.958(0.16-5.85) \\
1.19(0.32-4.45)\end{array}$ & $\begin{array}{l}\text { I } \\
1.52(0.22-10.64) \\
1.15(0.306-4.36)\end{array}$ \\
\hline Duration of surgery (minutes) & $\begin{array}{l}\leq 60 \\
60-120 \\
>120\end{array}$ & $\begin{array}{l}109 \\
124 \\
75\end{array}$ & $\begin{array}{l}10 \\
13 \\
21\end{array}$ & $\begin{array}{l}\text { I } \\
3.03(0.57-15.95) \\
3.68(1.10-12.27)\end{array}$ & $\begin{array}{l}\text { I } \\
3.392(1.45-7.94)^{*} \\
4.36(1.91-9.95)^{* *}\end{array}$ \\
\hline Adverse intraoperative event & $\begin{array}{l}\text { No } \\
\text { Yes }\end{array}$ & $\begin{array}{l}302 \\
6\end{array}$ & $\begin{array}{l}42 \\
2\end{array}$ & $\begin{array}{l}\text { I } \\
5.49(1.53-19.63)\end{array}$ & $\begin{array}{l}\text { I } \\
5.968(1.7 \mid-20.87)^{*}\end{array}$ \\
\hline
\end{tabular}

Note: $* P$-value $<0.05$, $* * P$-value $<0.001$.

Abbreviations: GA, general anesthesia; SA, spinal anesthesia; LA, local anesthesia.

study, $11.7 \%,{ }^{6}$ and lower than an African outcome cohort study which was $18.2 \% .^{23}$ The study was conducted in different parts of Ethiopia, and showed higher complication rate as compared to the current findings, which was $39.2 \%$ in Gondar teaching and referral hospital ${ }^{8}$ and $17 \%$ in Attat general hospital, Gurage zone. ${ }^{9}$ These discrepancies may be related to the relatively better quality of surgical care delivery and the presence of qualified health care workers at a tertiary hospital compared to primary and general hospitals in Ethiopia and others were studies comprising limited systems like post-laparotomy. ${ }^{8}$

The overall mortality rate following all types of surgery was $2.5 \%$. But the magnitude of death in patients who had already developed complications was significantly higher, $20.5 \%$. The high postoperative complication associated death rate could be attributed to the higher emergency cases with acute abdomen or trauma during the study period. The overall mortality is similar with large national based cohort studies, which was $2.8 \%$. This figure is by far lower compared to the study conducted throughout low and middle income countries (LMIC) as well as in developed countries, which ranges from $1.2-4.2 \%$ in developed countries and 9.5\% in developing countries. ${ }^{2,6}$

In our study, smoking was significantly associated with postoperative complications. It has been known and studies identified smoking is associated with different health risks including; postoperative wound complications, cardiopulmonary complications, and increased chance of admission to the intensive care unit. ${ }^{10,24-32}$ The nicotine component of cigarettes is responsible for such pulmonary, cardiovascular, and immune complications. ${ }^{26}$

This study revealed that the higher category of patient morbidity status increases the risk of postoperative complications. This finding is in agreement with astudy conducted by Wolters et $\mathrm{al}^{33}{ }^{33}$ which delineated the risk of complications has increased as the category of ASA morbidity status 
increases. Similarly, another study depicted that the higher class of ASA during preoperative time highly predicts the possible postoperative complication and patient's outcome. This might be attributed to patients' poor physical health condition on the preoperative time. ${ }^{17,18}$

This study unveiled that the longer duration of surgery, more than 2 hours, increases the chance of developing postoperative complications. This is in agreement with Kim et $\mathrm{al},{ }^{14}$ which demonstrated the longer operative time was associated with the step-wise increase in the risk of overall complications including reoperation, medical, surgical, and superficial surgical site infection. It is relatively higher among patients with emergency surgical intervention and it has a deleterious effect on the outcome according to the principle of damage control surgery, ${ }^{13,34}$ which was the case in this study.

The other factor which could have increased the chance of developing postoperative complications was intraoperative adverse events. This finding is in accord with those of Greenstein et al, ${ }^{15}$ which shows that patients with an adverse intraoperative event have greater risk of complication than those without an event. Similarly, Rampersaud et $\mathrm{al}^{16}$ reported that patients with adverse intraoperative event were more likelyto develop postoperative complications. Moreover, studies conducted in the United Kingdom and African countries showed there was increased mortality in patients operated on for emergency conditions and out of regular working hours. ${ }^{35,36}$

\section{Strength and Limitation of the Study}

This study was conducted using a prospective study design which produces a more reliable result. However, single health institution findings might not be generalized for the national figures. In addition, the patient prognosis after discharge from hospital was not known as followup was not done which could affect the whole picture.

\section{Conclusion and Recommendation}

The study has revealed high postoperative complication associated deaths, which could be due to higher emergency load of patients operated on as this set up is the only tertiary hospital. Length of operation time was found to be significantly associated with these complications. Therefore, applying the principles of damage control surgery for emergency operations is imperative to reduce the operative time which in turn decreases postoperative complications and associated deaths. In addition, patients who develop postoperative complications tend to stay longer in the hospital, being affected with increased cost and sometimes the inability to afford medications cost, which could be attributed to increased mortalities.

We recommend the cessation of cigarette smoking before elective surgeries and the government has to increase community awareness through mass community education to reduce the health risks of smoking. Lastly, we recommend future researchers to conduct a postoperative outcome study with multi-settings and a larger sample size which helps in developing national figures of postoperative complications.

\section{Abbreviations}

AOR, Adjusted Odds Ratio; ASA, American Society of Anesthesiologists; CI, Confidence Interval; COR, Crude Odds Ratio; SD, Standard Deviation; CDC, Center for Disease Control.

\section{Data Sharing Statement}

The datasets used for analyses during the current study are available from the corresponding author on reasonable request.

\section{Ethical Approval}

An ethical clearance was obtained with reference number REF.HFSUH0120/19 from the institutions management committee. Informed voluntary and written consent was obtained from each study participant. The respondents were assured of confidentiality by excluding their names during the data collection. A parent or legal guardian of patients under 18 years of age provided informed consent, and this study was conducted in accordance with the Declaration of Helsinki.

\section{Acknowledgments}

Above all we want to thank our participants who consented to participate in this study. Next will not pass without appreciating the effort of surgical residents of Haramaya University who helped in supervising the data collection and surgical ward nursing staff for their passionate care for the patients and supporting the data collectors.

\section{Author Contributions}

All authors made a significant contribution to the work reported, whether that is in the conception, study design, execution, acquisition of data, analysis and interpretation, 
or in all these areas; took part in drafting, revising, or critically reviewing the article; gave final approval of the version to be published; have agreed on the journal to which the article has been submitted; and agree to be accountable for all aspects of the work.

\section{Funding}

Hiwot Fana Specialized University hospital/College of Health and Medical Sciences has provided the stationary materials needed for the study.

\section{Disclosure}

The authors report no conflicts of interest in this work.

\section{References}

1. Reid J, Clarke J. Progressing safer surgery. J Perioper Pract. 2009;19 (10):336-341. doi:10.1177/175045890901901006

2. Pearse RM, Moreno RP, Bauer P, et al. Mortality after surgery in Europe: a 7 day cohort study. Lancet. 2012;380(9847):1059-1065. doi:10.1016/S0140-6736(12)61148-9

3. Pearse RM, Harrison DA, James P, et al. Identification and characterisation of the high-risk surgical population in the United Kingdom. Critical Care. 2006;10(3):1-6. doi:10.1186/cc4928. Epub 2006 Jun 2.

4. Klohnen A. New perspectives in postoperative complications after abdominal surgery. Vet Clin Equine Pract. 2009;25(2):341-350. doi:10.1016/j.cveq.2009.05.003.

5. Sansone A, Di Dato C, de Angelis C, et al. Smoke, alcohol and drug addiction and male fertility. Reproduct Biol Endocrinol. 2018;16 (1):3. doi:10.1186/s12958-018-0320-7

6. Ahmad T, Bouwman R, Grigoras I, et al. Global patient outcomes after elective surgery: prospective cohort study in 27 low-, middle-and high-income countries. Br J Anaesthes. 2016;117 (5):601-609. doi:10.1093/bja/aew316.

7. Lemma B-E, Deneke A, Negash K, et al. Situational analysis of emergency and essential surgical care in public Hospitals in Ethiopia. 2013.

8. Gebremedhn E, Agegnehu A, Anderson B. Outcome assessment of emergency laparotomies and associated factors in low resource setting. A case series. Ann Med Surg. 2018;36:178-184. doi:10.1016/j. amsu.2018.09.029

9. Gebrie T, Handiso T, Hagisso S. Management outcome and associated factors of surgically treated non traumatic acute abdomen at Attat Hospital, Zone, Ethiopia. Int J Surg Res Pract. 2019;6:099. doi:10.23937/2378-3397/1410099

10. Gajdos C, Hawn MT, Campagna EJ, Henderson WG, Singh JA, Houston T. Adverse effects of smoking on postoperative outcomes in cancer patients. Ann Surg Oncol. 2012;19(5):1430-1438. doi:10.1245/s10434-011-2128-y

11. Cai M, Zeng XY, Xiong Z, et al. [Early postoperative complications and risk factors in laparoscopic D2 radical gastrectomy for gastric cancer]. Zhonghua Wei Chang Wai Ke Za Zhi. 2019;22(8):742-747. Chinese. doi:10.3760/cma.j.issn.1671-0274.2019.08.008

12. Sandler RS, Maule WF, Baltus ME. Factors associated with postoperative complications in diabetics after biliary tract surgery. Gastroenterology. 1986;91(1):157-162. doi:10.1016/0016-5085(86) 90452-X

13. Boyd-Carson H, Gana T, Lockwood S, Murray D, Tierney G. A review of surgical and peri-operative factors to consider in emergency laparotomy care. Anaesthesia. 2020;75:e75-e82. doi:10.1111/ anae. 14821
14. Kim BD, Hsu WK, De Oliveira GS, Saha S, Kim JY. Operative duration as an independent risk factor for postoperative complications in single-level lumbar fusion: an analysis of 4588 surgical cases. Spine. 2014;39(6):510-520. doi:10.1097/BRS.0000000000000163

15. Greenstein AJ, Wahed AS, Adeniji A, et al. Prevalence of adverse intraoperative events during obesity surgery and their sequelae. $J$ Am Coll Surg. 2012;215(2):271-277. e3. doi:10.1016/j.jamcollsurg.2012.03.008

16. Rampersaud YR, Moro ER, Neary MA, et al. Intraoperative adverse events and related postoperative complications in spine surgery: implications for enhancing patient safety founded on evidence-based protocols. Spine. 2006;31(13):1503-1510. doi:10.1097/01.brs.0000220652.39970.c2

17. Rauh MA, Krackow KA. In-hospital deaths following elective total joint arthroplasty. Orthopedics. 2004;27(4):407-411. doi:10.3928/ 0147-7447-20040401-18

18. Zakriya KJ, Christmas C, Wenz JF, Franckowiak S, Anderson R, Sieber FE. Preoperative factors associated with postoperative change in confusion assessment method score in hip fracture patients. Anesth Analg. 2002;94(6):1628-32, table of contents. doi:10.1097/ 00000539-200206000-00050

19. Dandena F, Leulseged B, Suga Y, Teklewold B. Magnitude and pattern of inpatient surgical mortality in a tertiary hospital in Addis Ababa, Ethiopia. Ethiop J Health Sci. 2020;30(3):371-377. doi:10.4314/ejhs.v30i3.8

20. Burssa D, Teshome A, Iverson K, et al. Safe surgery for all: early lessons from implementing a national government-driven surgical plan in Ethiopia. World $J$ Surg. 2017;41(12):3038-3045. doi:10.1007/s00268-017-4271-5

21. Jammer I, Wickboldt N, Sander M, et al. Standards for definitions and use of outcome measures for clinical effectiveness research in perioperative medicine: European Perioperative Clinical Outcome (EPCO) definitions: a statement from the ESA-ESICM joint taskforce on perioperative outcome measures. Eur J Anaesthesiol. 2015;32(2):88-105.doi:10.1097/EJA.0000000 000000118

22. Horan TC, Andrus M, Dudeck MA. CDC/NHSN surveillance definition of health care-associated infection and criteria for specific types of infections in the acute care setting. Am J Infect Control. 2008;36 (5):309-332. doi:10.1016/j.ajic.2008.03.002

23. Biccard BM, Madiba TE, Kluyts H-L, et al. Perioperative patient outcomes in the African Surgical Outcomes Study: a 7-day prospective observational cohort study. Lancet. 2018;391(10130):1589-1598. doi:10.1016/S0140-6736(18)30001-1

24. Møller AM, Pedersen T, Villebro N, Munksgaard A. Effect of smoking on early complications after elective orthopaedic surgery. J Bone Joint Surg Br. 2003;85-B(2):178-181. doi:10.1302/0301-620X.85B2.13717

25. Grønkjær M, Eliasen M, Skov-Ettrup LS, et al. Preoperative smoking status and postoperative complications: a systematic review and meta-analysis. Ann Surg. 2014;259(1):52-71. doi:10.1097/ SLA.0b013e3182911913

26. Møller AM, Villebro N, Pedersen T, Tønnesen H. Effect of preoperative smoking intervention on postoperative complications: a randomised clinical trial. Lancet. 2002;359(9301):114-117. doi:10.1016/S0140-6736(02)07369-5

27. Lindström D, Azodi OS, Wladis A, et al. Effects of a perioperative smoking cessation intervention on postoperative complications: a randomized trial. Ann Surg. 2008;248(5):739-745. doi:10.1097/ SLA.0b013e3181889d0d

28. Moore S, Mills BB, Moore RD, Miklos JR, Mattox TF. Perisurgical smoking cessation and reduction of postoperative complications. Am $J$ Obstet Gynecol. 2005;192(5):1718-1721. doi:10.1016/j. ajog.2004.11.048

29. Møller A, Maaløe R, Pedersen T. Postoperative intensive care admittance: the role of tobacco smoking. Acta Anaesthesiol Scand. 2001;45 (3):345-348. doi:10.1034/j.1399-6576.2001.045003345.x 
30. Heng CK, Badner VM, Clemens DL, Mercer LT, Mercer DW. The relationship of cigarette smoking to postoperative complications from dental extractions among female inmates. Oral Surg Oral Med Oral Pathol Oral Radiol Endodontol. 2007;104(6):757-762. doi:10.1016/j. tripleo.2007.04.020

31. Mills E, Eyawo O, Lockhart I, Kelly S, Wu P, Ebbert JO. Smoking cessation reduces postoperative complications: a systematic review and meta-analysis. Am J Med. 2011;124(2):144-154. e8. doi:10.1016/ j.amjmed.2010.09.013

32. Sharma A, Deeb A-P, Iannuzzi JC, Rickles AS, Monson JR, Fleming FJ. Tobacco smoking and postoperative outcomes after colorectal surgery. Ann Surg. 2013;258(2):296-300. doi:10.1097/ SLA.0b013e3182708cc5
33. Wolters U, Wolf T, Stützer H, Schröder T. ASA classification and perioperative variables as predictors of postoperative outcome. $\mathrm{Br}$ J Anaesth. 1996;77(2):217-222. doi:10.1093/bja/77.2.217

34. Griffin TJ, Cheung WS, Zavras AI, Damoulis PD. Postoperative complications following gingival augmentation procedures. J Periodontol. 2006;77(12):2070-2079. doi:10.1902/jop.2006.050296

35. Chana P, Joy M, Casey N, et al. Cohort analysis of outcomes in 69 490 emergency general surgical admissions across an international benchmarking collaborative. BMJ Open. 2017;7(3):e014484. doi:10.1136/bmjopen-2016-014484

36. Tevis SE, Kennedy GD. Postoperative complications and implications on patient-centered outcomes. J Surg Res. 2013;181 (1):106-113. doi:10.1016/j.jss.2013.01.032
Open Access Surgery

\section{Publish your work in this journal}

Open Access Surgery is an international, peer-reviewed, open access journal that focuses on all aspects of surgical procedures and interventions. Patient care around the peri-operative period and patient outcomes post-surgery are key topics for the journal. All grades of surgery from minor cosmetic interventions to major surgical procedures are covered. Novel techniques and the utilization of new

Submit your manuscript here: https://www.dovepress.com/open-access-surgery-journal
Dovepress

instruments and materials, including implants and prostheses that optimize outcomes constitute major areas of interest. The manuscript management system is completely online and includes a very quick and fair peer-review system, which is all easy to use. Visit http://www.dovepress.com/testimonials.php to read real quotes from published authors. 